Antônio Gomes da Silva

Mestre em Filosofia. Professor do

Departamento de Sociologia e Antropologia/UFPB Campus II.

Pesquisador do Laboratório de

Ciências da Cognição.

E-Mail:gomero@ch.ufpb.br
-

\title{
$A$ irrupção do mítico e as muitas faces do homem
}

Iniciarei esta conversa com uma "história assombrada" cuja anotação é de Luís da Câmara Cascudo.

"Uma das estórias mais extraordinárias é a do vaqueiro José Francisco de Paula, morador da fazenda São Tomé, município de Santa Cruz, no Rio Grande do Norte, ponto obrigatório de passagem pelos comboieiros e compradores de sal e de peixe-voador. No alpendrado, quase sempre, estavam cinco ou seis vaqueiros ou mascateadores, que, depois da ceia, contavam casos e brigas. Uma noite em que José Francisco estava apenas com sua mulher ouviu-se o latido desenfreado dos grandes cães de caça que o sertanejo possuía. Não prestou atenção. Em cada semana, na noite da quinta para sexta-feira, os cães 'acuavam' furiosamente. José Francisco, numa noite alta, entreabriu a janela e viu passar, seguido pela matilha enfurecida, um animal corpulento, meio baixo, roncando e batendo insistentemente as largas orelhas de burro. Vindo, dias depois, um comboio arranchar-se na fazenda, José Francisco contou o episódio. Era a noite fatídica. Um dos comboieiros explicou que o bicho batera em boa porta. Ele trazia justamente cera benta e, besuntando as balas da 'Winchester', declarou-se pronto para desencantar o fantasma. Ao nascer da lua, pelas onze e tanto, ouviram a trovoada dos cães de caça e a marcha resfolegada de um animal pesado. Saíram todos e fizeram tocaia. O vaqueiro escolhido escondeu-se perto duma barranca do rio, agora seco pelo verão escaldante. De repente um vulto negro passou, sacudindo as orelhas. Descargas estrondaram, clareando o escurão que o luar não vencera. O bicho, incólume, rumara, num rosnado aterrador, caminho do rio. O vaqueiro, dormindo na pontaria, alvejou-o com um tiro fulminante. O animal, num ronquejo horrendo, caiu pela barranca abaixo, estre- buchando. Correram todos, com archotes. Era um Lobisomem. A bala com a cera benta matara-o. Ferido pela morte não se desanimalizara inteiramente. Da cintura para baixo semelhava um porco, sarrudo, cheio de lama e de garranchos, sujo de cascas, as patas firmemente cravadas na areia fofa do rio. Da cintura para cima era um homem moreno-claro, forte, de nariz aprumado, cabeleira fina, anelada, as mãos fechadas na última convulsão. Enterraram-no ali mesmo, sem cruz, sob montão de pedras, sinalizando o local exato da tragédia inacreditável. José Francisco de Paula mudou-se para Estivas, no município de Ceará-Mirim, onde morreu, anos depois, sem nunca esquecer a noite da caçada impressionante."1

A primeira questão que proponho para esta história assombrada é: qual a trama substantiva - ou quais as tramas substantivas - que se nos

- ${ }^{1}$ CASCUDO, Luís da Câmara. Geografia dos Mitos Brasileiros. 2 ed. Rio de Janeiro, José

- Olympio Editora, 1976. pp. 160-161. 
dá esta história, no que se refere aos seus aspectos míticos? Esta primeira questão, por seu turno, já exige alguns esclarecimentos. O que quero dizer com aspectos míticos? O que são tramas substantivas? O que é algo que nos dá, quando referido a aspectos míticos e a tramas substantivas?

Em pronunciamentos anteriores ${ }^{2}$ defendi, dentre outras noções específicas a cada caso, a idéia genérica segundo a qual o mítico se esboça por seu caráter de sagrado, verdadeiro e modelar. O primeiro atributo do mítico, no entanto, é a sua sacralidade. A sacralidade do mítico, por sua vez, é o concernente às coisas divinas - divino no sentido amplo de sobrenatural, o sublime como o monstruoso ${ }^{3}$; e o sobrenatural enquanto irrupção no mundo dos homens, enquanto epifania. Ora, assinalar o sagrado enquanto irrupção no mundo dos homens é já falar de uma trama substantiva que institui e constitui este mesmo mundo; institui e constitui no sentido de dar começo a, estabelecer, criar, fundar; ser base, parte essencial, consistência e representação. O mundo dos homens, o mundo das vivências humanas é já a esfera das tramas substantivas - ou seja, a esfera das tramas significativas. A esfera das tramas significativas, o que denominamos propriamente Mundo, instituída e constituída pari passu com o humano, é, desde sempre, o que se dá como vivência a cada um de nós, em nossa experiência de fundar e fundamentar - isto é, criar e justificar - nossas próprias vidas. Trama, ainda, no sentido de sustentar-se tão somente enquanto relação e reciprocidade; jamais como determinação única ou isolada.

Podemos voltar, então, à questão das tramas significativas que nos são assinaladas pela história de assombração anotada por Cascudo. O primeiro elemento da trama mítica em que o homem se vê enredado é que, de início, o sobrenatural irrompe no mundo sem aviso prévio, pelo que não é ainda compreendido como tal: "Uma noite (...) ouviu-se o latido desenfreado dos grandes cães de caça que o sertanejo possuía. Não prestou atenção". Ora, fosse a irrupção mítica isolada ou fortuita, permaneceria incompreendida, desconhecida, sem qualquer significado para o humano. Mas o mítico se repete, força passagem para o mundo dos homens: "Em cada semana, na noite da quinta para sextafeira (...)". E repete-se a tal ponto que, finalmente, aparece no horizonte do homem, faz-se presente para o homem - ainda que, de início, se faça presente apenas como pré-sentimento, como primeiro sentimento, como forma de um 'conhecimento' primeiro, diríamos: “(...) numa noite alta, entreabriu a janela e viu passar, seguido pela matilha enfurecida, um animal corpulento, meio baixo, roncando e batendo insistentemente as largas orelhas de burro". Observe-se, no entanto, que este pré-sentimento, esta forma primeira - no sentido de que será mais tarde secundada por uma outra forma - de conhecimento, é como que contemplativa, no preciso sentido de que não induz, ainda, o homem à ação: “(...) entreabriu a janela e viu passar ...". Por isto se diz: é um mero pré-sentimento; e ainda: será mais tarde secundada por uma outra. Até que o homem decide-se por enfrentar o seu destino, aquilo que lhe cabe como escolha ante o que o mundo lhe propõe, ante o que lhe épresente: “(...) trazia justamente cera benta e, besuntando as balas da 'Winchester', declarou-se pronto para desencantar o fantasma". O sobrenatural, então, nos aparece como tal: enquanto 'problema' que instiga o homem à ação; enquanto 'O Outro' que resiste à ação humana. É somente a partir deste

O Sagrado e o Profano na Literatura Popular do Nordeste Brasileiro. Recife, V Encontro de Antropólogos do Norte e Nordeste, 1997.; O Ciclo Mítico da Maldade Castigada na Literatu- ra Popular do Nordeste Brasileiro. Fortaleza, VII Encontro de Ciências Sociais do Norte e - Nordeste, 1997.; O Caráter Mítico da Narrativa Popular do Nordeste Brasileiro. Campina - Grande, I Semana de Ensino, Pesquisa e Extensão, 1997.; Histórias de Assombração: "verda- de" e "sacralidade" na narrativa mítico-popular do Nordeste brasileiro. Recife, IV Encontro

- Nordeste da APIPSA, 1997.; Linguagem e Mito: a narrativa popular do Nordeste brasileiro. - Campina Grande, VI Semana de Letras, 1997. Capítulo primeiro, intitulado A Estrutura dos Mitos, seções 3 e 7, Tentativa de definição do mito e Estrutura e função dos mitos, respectivamente. 1 CASCUDO, Luís da Câmara. Geografia dos Mitos Brasileiros. 2 ed. Rio de Janeiro, José Olympio Editora, 1976. pp. 160-161. 
momento que podemos afirmar a facticidade do mítico, quando manifesta-se a sua capacidade de induzir à ação. De mero pré-sentimento torna-se indutor da ação; enquanto problematizador do mundo do homem, orienta este mesmo homem à busca de um sentido - sentido para o présentimento, para a ação, para o próprio mundo que relacional e reciprocamente se dá e se faz através desta ação; orienta, pois, a própria ação. Este estágio ocorre desde que "(...) ao nascer da lua, pelas onze e tanto, ouviram a trovoada dos cães de caça e a marcha resfolegada de um animal pesado (...)”; até que “(...) ferido pela morte não se desanimalizara inteiramente. Da cintura para baixo semelhava um porco, sarrudo, cheio de lama e de garranchos, sujo de cascas, as patas firmemente cravadas na areia fofa do rio. Da cintura para cima era um homem moreno-claro, forte, de nariz aprumado, cabeleira fina, anelada, as mãos fechadas na última convulsão". O humano instaura e vence seu próprio destino; o homem, desse modo, prevalece das forças monstruosas que o assaltam; e o sobrenatural, por fim, é assimilado ao mundo humano: “(...) enterraram-no ali mesmo, sem cruz, sob montão de pedras, sinalizando o local exato da tragédia inacreditável". O homem está reconciliado com as suas forças e com o seu mundo, com as suas luzes e com a sua face obscura; o homem, que criou-se, pode agora justificar-se de si para si mesmo.

Que relações estabelecer entre tais elementos e o mundo, o meu mundo? De que modo isto se apresenta? Como me afeta? A irrupção de algo no mundo implica, primeira e necessariamente, em presença e re- lação do que irrompe no meu mundo, para comigo, em face de mim. A irrupção da trama mítica no mundo, no meu mundo, é então uma prova que me dou de que há mundo, ao menos um mundo, o meu mundo. O irromper como trama torna evidente para mim, a um só tempo, que existo, mas que existo como relação, enquanto interação para com O Outro no mundo. No caso considerado, com vários Outros e até vários Eus. O que significa dizer, manifestamo-nos O Outro, o mundo e $E u$ como luzes e como sombras, como similaridade e diferença, como proximidade e como distância, como interior e como exterior. Manifestamo-nos O Outro, o mundo e $E u$, singular ou pluralmente, como potências afirmativas, construtivas, criativas, instauradoras do mundo humano, que é o meu próprio mundo; e, indeslindavelmente, como potências tenebrosas, destrutivas, obscuras, desestabilizadoras do mundo dos homens, do meu próprio mundo.

Que potências afinal são estas, mobilizadas pela narrativa do lobisomem? Sabe-se, desde o princípio, que forças construtivas e destrutivas se manifestam, que luzes e sombras se fazem representar, que as possibilidades instauradoras e também as desestabilizadoras do mundo humano, do meu mundo, se fazem patentear. Qual a fonte de onde jorram estas forças, qual o sentido que se delineia sob o impulso das suas manifestações? As fontes do mundo humano são o próprio homem, as forças humanas conjugadas. As forças físicas, as forças psíquicas, as forças morais, as forças espirituais o desejo, a vontade, a fé.

O lobisomem traz consigo a ambivalência do lobo e do homem. É lupus homo, homem lobo; homem que se transforma em lobo. Nunca é demais lembrar, além disso, que nos começos da vida, como nos dias atuais, o homem, tanto quanto o lobo, sobrevive da vida do Outro. O homem, de modo similar ao lobo, precisa matar para comer - o boi, o carneiro, o fruto, a erva -; tanto quanto o lobo, precisa desenvolver e projetar a sua agressividade - ainda que de um modo socialmente tolerável e até produtivo. Esta semelhança, esta ambivalência, claramente, não é vivida sem dor; é preciso exorcizar a ambivalência, é preciso minimizar a dor. Nada mais compreensível, portanto, que esta necessidade humana de lançar fora de si, longe de si, esta sensação de ter uma fera na alma, de ser uma fera em alma: projeta-a, então, na figura mítica do lobisomem, que pode morrer em lugar do humano, em meu lugar; e enquanto morre em lugar do humano, em meu lugar, leva para longe, ritualisticamente, em imaginação, a ferocidade imanente ao modo humano de ser. Daí que tão logo se manifesta o lobofera no horizonte do humano, logo lhe é dado combate, depressa é abatida a fera ou desencantada isto é, humanizada.

Quem são estes Outros e estes Eus que se patenteiam ao longo do narrado? De início podemos afirmar que os Outros e mesmo os Eus são expressão - melhor, são modo de ser, 
de existir, de atualizar-se, de manifestar-se - destas várias potências, positivas e negativas, construtivas e destrutivas, instauradoras e desestabilizadoras que habitam dentro de mim como dentro de cada um de nós. O lobo é o Outro que me cerceia, me limita, me agride; o lobo sou Eu enquanto cerceamento, limitação e agressão para com o Outro e mais, a mim mesmo: enquanto cerceio, limito e agrido a mim mesmo e à minha circunstância. Eu sou vários, como o Outro não se reduz à unicidade; tenho minhas faces construtivas e minhas faces destrutivas, como todos nós; tenho meu lado lobo e meu lado homem, como todos nós. Os muitos Eus e os muitos Outros são expressão das muitas potências físicas, psíquicas, morais que fervilham dentro de cada um de nós.

Mas, qual o mundo específico dentro de que faz sentido a história do lobisomem? O mundo mítico é o mundo dos afetos; é a esfera da existência humana em que tudo se relaciona com tudo de forma imediata, logo tudo afeta a tudo. Mundo posto para além dos modos atualmente predominantes de racionalidade, cria sua própria racionalidade, impenetrável à lei das causas e dos efeitos. Identifica-se, por isto, com o nosso velho mundo pré-científico e, na atualidade, com uma determinada instância que se nos dá para além do científico. O mundo dos afetos, hermético à lei de causa e efeito, se nos dá, se me dá, como o que nos afeta, como o que me afeta, em nossas vivências, no meu vivido. A dimensão mítica, desse modo, se dá no mundo do vivido, enquanto afeta as nossas vivências, enquanto impulsiona e orienta as nossas ações. Claramente não se põe a questão da aceitação de histórias de lobisomem como verdade objetiva, exceto, talvez, para restritas parcelas do humano.

Mas, vale lembrar, onde mais se manifesta a agressividade - a lupinidade - humana, nos dias que correm, senão onde mais se afirma o moderno, o científico, o tecnológico, o progresso? O declínio do mundo mítico-ou, mais especificamente, da inserção mítica do homem no mundo - não implica no cancelamento das forças que conduziram este mesmo homem às suas construções míticas. A relação do humano para com estas forças é que se tornou mais precária. Reduzindo-se as possibilidades de reconciliação do homem para consigo mesmo, que têm como uma das formas de via- bilização a perspectiva mítica do mundo e da vida, encontra-se o humano, mais do que nunca, entregue ao turbilhão das forças cegas que lhe impelem para a frente, para o mundo e para O Outro, forças estas que, hoje, tão freqüentemente explodem nas manifestações mais extremas de irracionalidade, de incompreensão, de intolerância - numa palavra, de barbárie.

Desse modo, finalizo esta nossa conversa com uma outra narrativa mítica, a narrativa do lobisomem, reconstruída desde a perspectiva do mítico como apreensão e expressão do mais vivencialmente humano, das forças que nos estabelecem no mundo e estabelecem o próprio mundo; a história do lobisomem como relação, acordo e conciliação do homem para consigo mesmo, de suas forças construtivas e as destrutivas, de suas luzes e suas sombras, de sua face lobo e sua face homem.

\title{
O Lobisomem Que Virou Homem
}

\author{
Quando os bosques cobriam a Terra \\ Quando o Homem e a Natureza eram Irmãos \\ Nasceu nosso irmão Lobo \\ Nasceu o irmão Homem \\ Nasceu o Lobisomem. \\ A frente, as árvores \\ Atrás, as árvores \\ Direita, esquerda, abaixo dos pés \\ As árvores, mais árvores \\ Grandes árvores. \\ Lá no alto, filtrado, \\ vez por outra, um raio de Sol. \\ Mais no alto, bem mais alto,
}


Encoberto, nublado,

Escondido, azulzinho do Céu.

Grandes árvores, mais árvores!

Come frutos, muitos frutos,

E folhas, e flores, e cascas

Nosso primo, primeiro,

Só come vegetal.

Mas quer mais, quer mais mundo!

Corre da floresta, o Homem, para o Mundo,

O espaço aberto, a vida aberta

A planície, o vale, a pradaria...

Corre mundo, desafio profundo.

Menos árvores, poucas árvores

Grama rala, mato ralo

$E$ as feras, muitas feras, grandes feras

E a morte... e a fome, e a vida.

Para viver, animais matam e comem animais.

O Homem está entre as feras,

O Homem é uma fera.

Entre os lobos, os leões, o touro bravo

O Homem é um lobo

O Homem é o Lobisomem.

Grandes feras, mais feras!

Come carne, muita carne

Veste peles, lasca pedras

Nosso primo, primeiro,

Mata e come outros animais.

Mas quer mais, muito mais!

Derruba a floresta, afasta as feras,

Planta o grão, domestica os bichos

Faz as cidades, domestica a si mesmo...

Faz o seu próprio mundo, desafio profundo.

Os bosques já não cobrem a Terra

O Homem e a Natureza já não são Irmãos.

Mas ainda dorme um irmão Lobo

No peito que bate de cada irmão Homem:

Cada um, a um só tempo, é Lobo, é Homem, é Lobisomem. 